\title{
Rancang Bangun Jari-Jari Velg Sepeda Menggunakan Material Kayu
}

\author{
Catur Setyawan K., Ikumbang Ferry P, Sukiswo \\ Program Studi Pendidikan Teknik Mesin FT Universitas Negeri Jakarta \\ catursk@gmail.com
}

\begin{abstract}
ABSTRAK
Pada penelitian ini akan dirancanga sebuah velg sepeda dengan jari-jari yang terbuat dari kayu. Jari-jari velg sepeda yang terbuatdari kayu diharapkan dapat menekan terjadinya pemanasan global. Jari-jari velg sepeda kayu yang akan dibuat terlebih dahulu ditentukan ukurannya dengan gambar 2 dimensi menggunakan software Autocad. Desain gambar yang sudah dibuat 2 dimensi kemudian dibuat pemodelan 3 dimensi dan dianalisis dengan menggunakan software Inventor. Proses pembuatan jari-jari velgsepeda kayu dilakukan dengan melihat disain awal yang sudah dibuat dan diuji sesuai dengan SNINo. 1049:2008 tentang roda dan ban.

Proses pembuatan jari-jari velg sepeda dilakukan dengan membuat pola yang dibuat dengan software Autocad dan menggunakan software Inventor dalam menentukan perakitan bagian velg serta analisis desain untuk mengetahiu apakah desain yang dibuat memiliki nilai safety factor yang aman untuk dilanjutkan ke proses pembuatan jari-jari velg sepeda kayu. Setelah jari-jari velg sepeda dirakit dengan mengacu pada desain yang dibuat pada software Inventor kemudian velg sepeda diuji sesuai dengan standar SNINo. 1049:2008 tentang roda dan ban
\end{abstract}

Kata kunci : kayu, velg sepeda

\section{PENDAHULUAN}

Melihat dari adanya konsep go green untuk menanggulangi dampak dari pemanasan global, maka banyak produk yang dirancang dengan menerapkan green technology seperti pembuatan dan penggunaan sepeda. Salah satu jenis sepeda yang sesuai dengan konsep ramah lingkungan yaitu sepeda kayu. Selain materialnya relatif murah, mudah didapat, dan mudah didaurulang, proses pembuatan sepeda kayu tidak menimbulkan carbon trace yang tinggi seperti pembuatan sepeda besi yang terbuat dari logam.

Pemilihan material kayu sebagai bahan baku pembuatan dimaksudkan sebagai alternatif dari material logam yang pada proses pembentukannya menimbulkan banyak polusi. Pemilihan material kayu sebagai alternatif dari besi juga dikarenakan kayu cukup kuat dan ringan untuk dijadikan bahan pembuat bagian sepeda kayu dan proses pembentukan kayu cukup mudah untuk dikerjakan.

Perancangan, pembuatan dan pengujian jarijari velg sepeda yang terbuat dari kayu akan diaplikasikan pada sepeda jenis road bike. Untuk mengetahui kekuatan desain dari jari-jari velg sepeda kayu, dilakukan analisis menggunakan software Inventor 2012. Pegujian beban dan pengujian impact pada jari-jari velg sepeda kayu untuk mengetahui kekuatan dari jari-jari velg sepeda kayu sesuai dengan desain yang dirancang mampu menahan bobot hingga $70 \mathrm{~kg}$ dan benturan dari ketinggian hingga $20 \mathrm{~cm}$ sehingga akan diketahui kelayakan dari jari-jari velg sepeda kayu sebagai alternatif dari jari-jari velg sepeda berbahan logam.

\section{METODOLOGI}

Penelitian ini bertujuan menganalisis jari-jari velg sepeda kayu pada sebuah sepeda jenis road bike yang berbahan kayu dengan menggunakan software Inventor, sehingga didapatkan desain jarijari velg yang tepat untuk pembuatan jari-jari velg sepeda berbahan kayu. Diagram alur penelitian ditunjukkan pada gambar 1 .

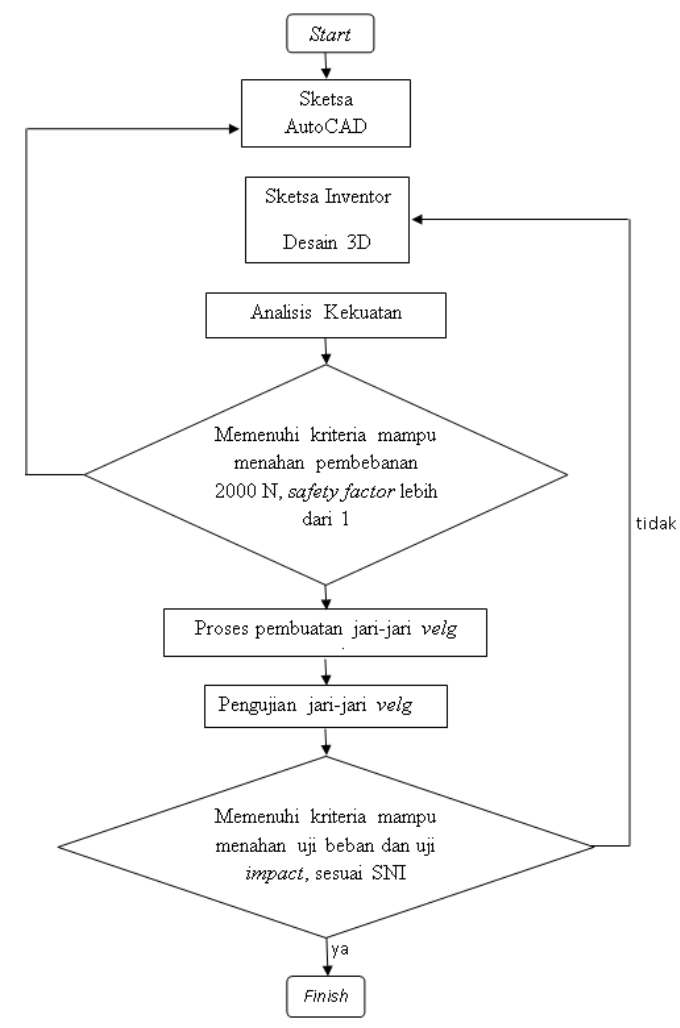

Gambar 1 Diagram alir penelitian 
Pada diagram ini ditunjukkan kegiatan dalam rancangn bangun velg kayu antara lain:

1. Pembuatan Desain 2D Menggunakan software AutoCAD

Pembuatan desain 2 dimensi sepeda dengan menggunakan software AutoCAD bertujuan untuk menentukan ukuran jari-jari velg sepeda kayu dari tiap pandangan. Dengan membandingkan dengan velg sepeda road bike velg standar, sehingga didapatkan desain 2 dimensi jari-jari velg sepeda yang diinginkan.

2. Pembuatan Desain 3D Menggunakan software Inventor 2012

Pembuatan desain 3 dimensi dengan menggunakan software Inventor bertujuan agar desain yang sudah dibuat sebelumnya pada desain 2 dimensi dapat dianalisis kekuatannya terhadap tekanan, serta mempermudah dalam proses pembuatan jari-jari velg sepeda kayu tersebut.

3. Analisis kekuatan jari-jari velg sepeda kayu

Desain 3 dimensi jari-jari velg sepeda kayu yang telah dibuat kemudian dianalisis dengan menggunakan software Inventor untuk mendapatkan nilai kekuatan, nilai kekuatan dari analisis desain yang dibuat berupa nilai tegangan von mises, displacement serta safety factor yang dapat digunakan sebagai acuan untuk proses selanjutnya dalam pembuatan jari-jari velg sepeda kayu.

4. Proses Pembuatan jari-jari velg sepeda kayu

Proses pembuatan velg sepeda kayu dilakukan sesuai dengan bentuk dan ukuran yang telah dibuat pada software Inventor agar mendapat hasil bentuk bagian-bagian jari-jari velg kayu yang sesuai dan ukuran yang presisi. Sehingga akan memudahkan dalam proses perakitan jari-jari velg sepeda kayu.

\section{Pengujian jari-jari velg sepeda kayu}

Pengujian dilakukan untuk memastikan jarijari velg sepeda kayu yang dibuat sesuai dengan desain rancangan awal yang dibuat dan mampu untuk menahan beban pada saat pengujian, baik uji impact maupun uji pembebanan.

a. Pengujian impact terhadap velg sepeda kayu

Pengujian impact bertujuan untuk memastikan jari-jari velg sepeda kayu yang dibuat dapat bertahan terhadap benturan saat dijatuhkan dari ketinggian tertentu. Pengujian dilakukan dengan menjatuhkan velg sepeda kayu dari ketinggian yang bervariasi. Jarak ketinggian velg sepeda kayu dari permukaan terus ditambah $2 \mathrm{~cm}$ tiap siklus pengujian. Pengujian dilakukan sampai ketinggian maksimum $20 \mathrm{~cm}$.

\section{b. Pengujian beban statis}

Pengujian dilakukan dengan memberi beban yang bervariasi. Beban berupa pasir yang dimasukkan ke dalam dua buah karung, kemudian diikatkan pada sisi-sisi sepeda secara merata (sisi kanan dan kiri sama beratnya). Beban yang diberikan ditambah bobotnya secara bertahap, dengan penambahan sebesar $10 \mathrm{~kg}$ tiap siklus pengujian.

\section{c. Pengujian roda}

Pengujian roda dilakukan dengan cara mengukur pergerakan roda berupa eksentrisitas dan ruang bebas roda. Pengukuran eksentrisitas dilakukan dengan cara mengukur pergerakan roda ke atas dan ke bawah tidak boleh lebih dari $4 \mathrm{~mm}$ diukur pada posisi terluar dari roda termasuk bannya. Untuk pengukuran ruang bebas roda dilakukan dengan cara mengukur jarak terdekat ban bagian luar dengan bagian garpu tidak boleh kurang dari $2 \mathrm{~mm}$.

\section{d. Pengujian ban dalam dan ban luar}

Pengujian ban dalam dan ban luar dilakukan dengan memompa dengan tekanan $110 \%$ dari tekanan maksimum yang tercantum pada dinding ban. Tekanan itu dipertahankan selama minimum 5 menit dan ban harus tetap menyatu dengan baik pada velg.

\section{PROSES PERANCANGAN}

Velg merupakan lingkaran tempat menempelnya ban pada ujung luar dari jari-jari roda. Velg menjaga agar perputaran dari ban tetap stabil. Untuk itu pembuatan modelnya harus dimodelkan dengan desain 2D menggunakan Software AutoCAD agar didapat ukuran jari-jari velg sepeda yang presisi.

Dalam pembahasan ini diambil part-part yang dirasa penting dari part-part yang ada yaitu: jari-jari velg, hub velg, rim velg, dan pengunci hub.

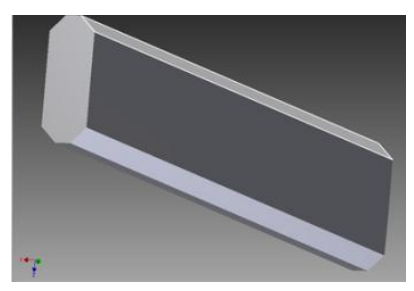

Gambar 2. Jari-jari velg 


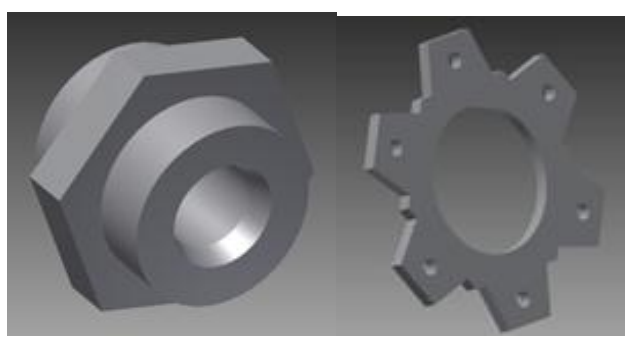

Gambar 3. Hub dan pengunci hub

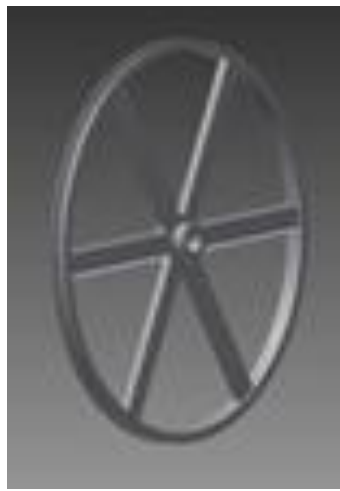

Gambar 4. Velg sepeda

Analisis terhadap desain jari-jari velg bertujuan untuk melihat kekuatan dari desain yang dibuat agat dihasilkan desain yang memenuhi standar. Analisis dilakukan menggunakan software Inventor 2012 dengan beban sebesar $2000 \mathrm{~N}$.

Desain jari-jari velg 3D yang sudah dibuat sebelumnya kemudian dianalisis dengan menggunakan software Inventor dan didapatkan nilai tegangan von mises sebesar $11.43 \mathrm{ksi}$

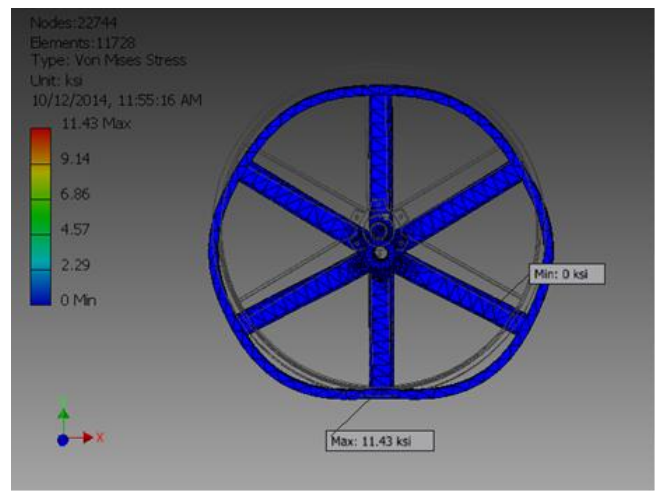

Gambar 5 Hasil analisi tegangan von mises

Desain jari-jari velg 3D yang sudah dibuat sebelumnya kemudian dianalisis dengan menggunakan software inventor dan didapatkan nilai displacemen sebesar 0.003942 in

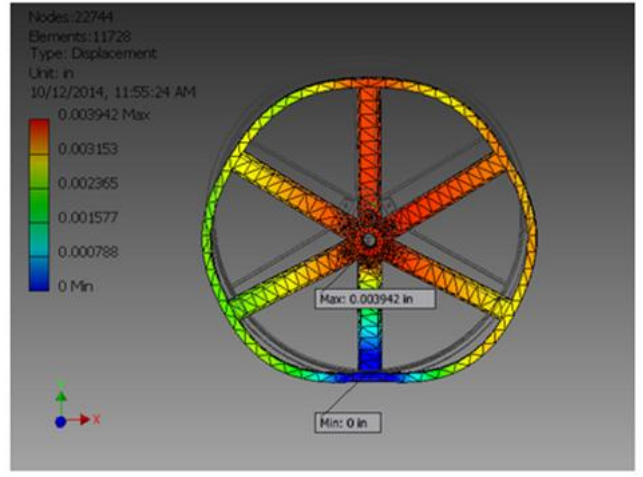

Gambar 6 Hasil nilai displacement

\section{PROSES PEMBUATAN}

1) Penentuan jenis kayu

Kayu yang digunakan untuk pembuatan jarijari velg sepeda kayu adalah jenis kayu jati belanda. Kayu jati belanda dipilih karena memiliki tekstur serat yang halus, ringan, mudah dibentuk sesuai dengan ukuran pada desain dan banyak tersedia.

\section{2) Pembuatan desain}

Pembuatan desain bertujuan agar ukuran benda yang dibuat lebih presisi dan menghasilkan bentuk yang sesuai dengan desain yang dibuat.

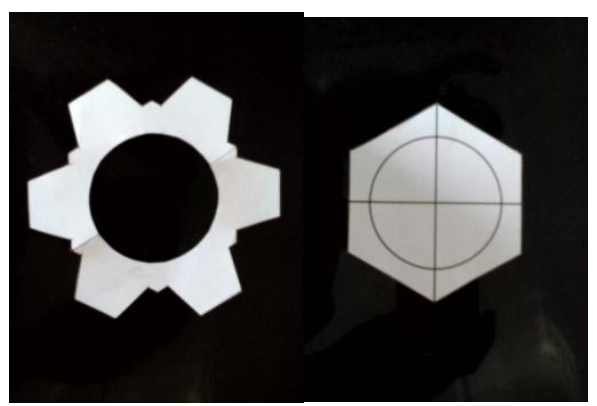

Gambar 7Pola desain 2D

3) Pemotongan sesuai desain

Kayu jati belanda dibentuk sesuai dengan pola dan ukuran yang telah dibuat sebelumnya. Pemotongan bentuk dilakukan menggunakan ukuran yang dibuat pada software Inventor.

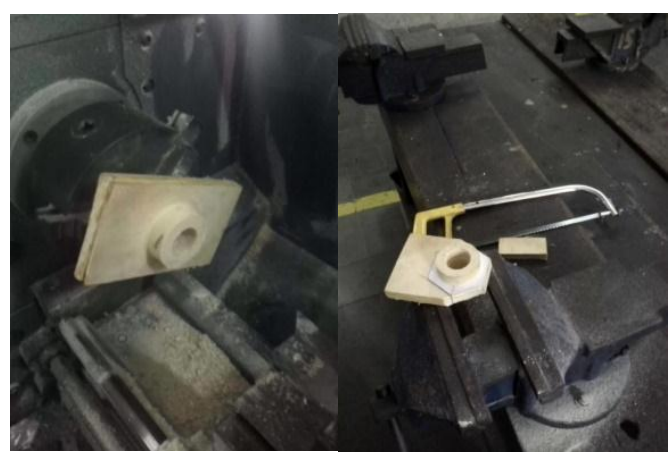


Gambar 8 PembubutanBentuk adaptor hub

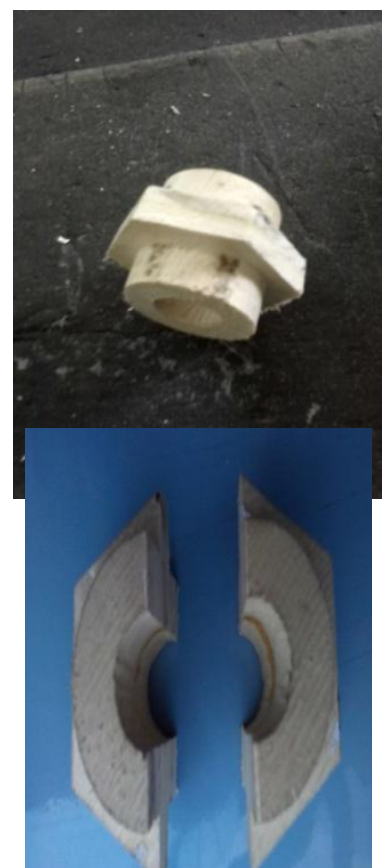

Gambar 9 Hasil pemotongan bentuk adaptor hub

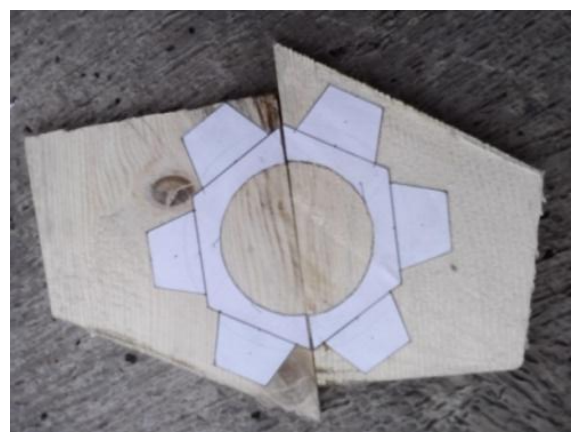

Gambar 10 Penempelan pola pengunci

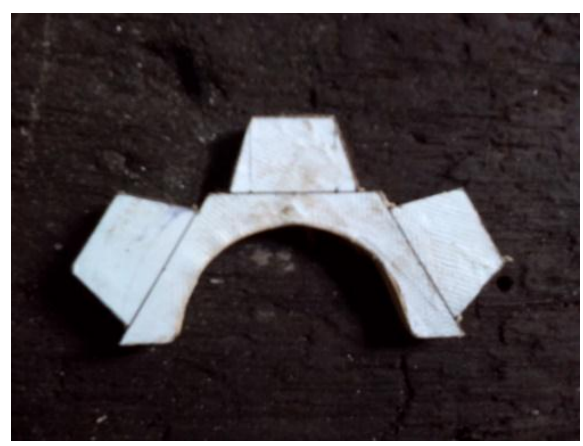

Gambar 11 hasilpemotonganpengunci

4) Pengelemankayu pada hub dan rim

Proses penempelan kayu pada bagian velg dilakukan dengan lem. Pengeleman dilakukan untuk merekatkan bagian-bagian dari velg kayu yang telah dibuat.

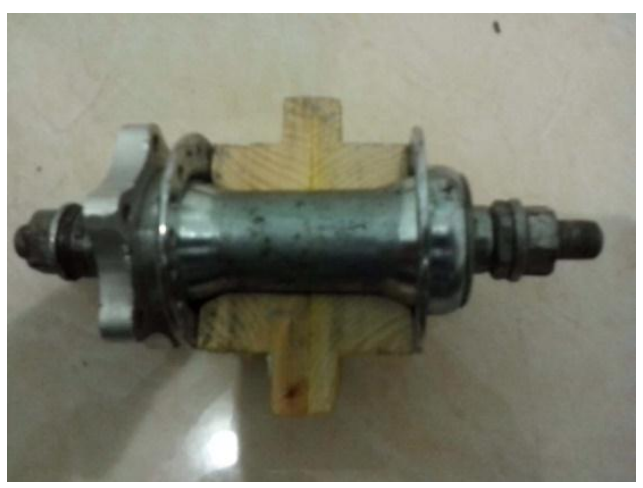

Gambar 12 Pemasangan adaptor pada hub

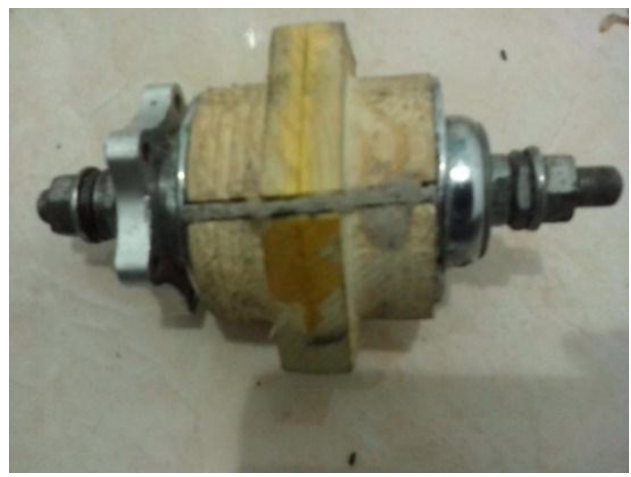

Gambar 13 Pengeleman adaptor pada hub

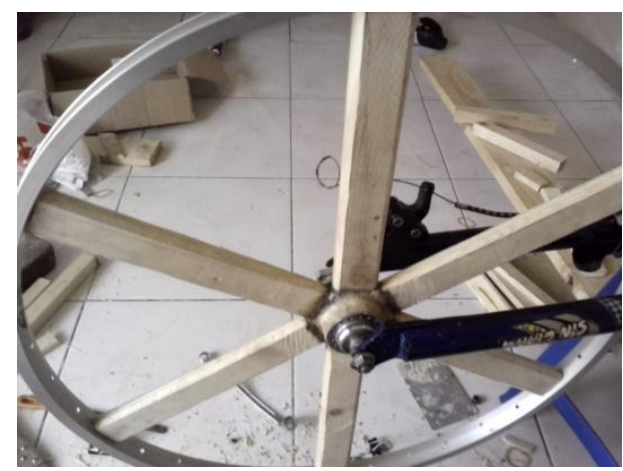

Gambar 14 Pengeleman jari-jaripada hub dan rim

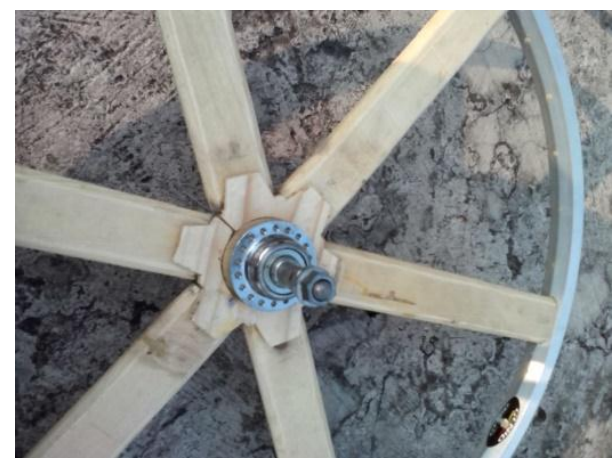

Gambar 15 Hasilpengelemanpenguncipada jari-jari

5) Pemasangan baut pengunci

Pemasangan baut dilakukan untuk memperkuat sambungan antara bagian-bagian dari velg sepeda kayu. Baut yang digunakan berdiameter $6 \mathrm{~mm}$ dan panjang $4 \mathrm{~cm}$. 


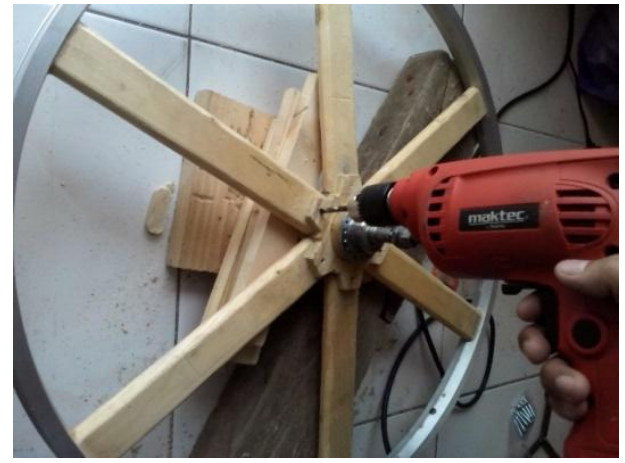

Gambar 16 Pengeboran bagian pengunci Jari-jari

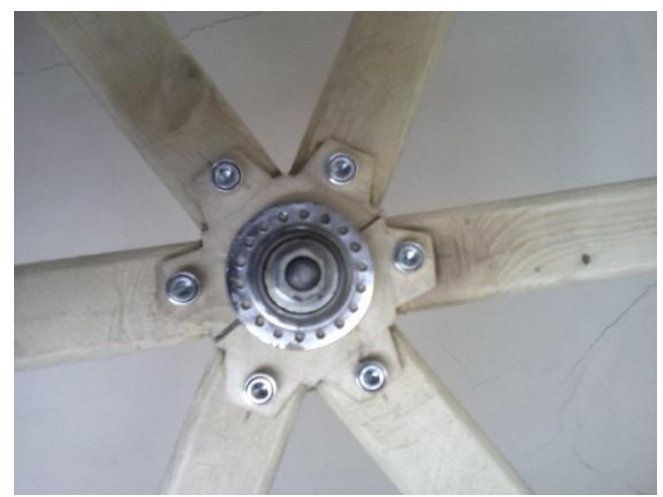

Gambar 17 Pemasangan baut pada pengunci Jarijari

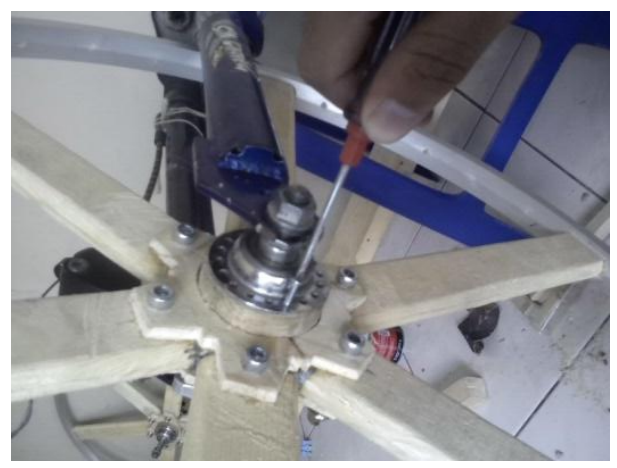

Gambar 18 pemasangan baut pada hub

6) Proses balancingvelg

Proses balancing dilakukan untuk menstabilkan putaran velg pada satu garis simetris. Proses balancing dilakukan dengan memutar velg sehingga dapat diketahui yang menunjukkan belum stabilnya velg sehingga perlu diaturnya jari-jari velg untuk menstabilkan putaran.

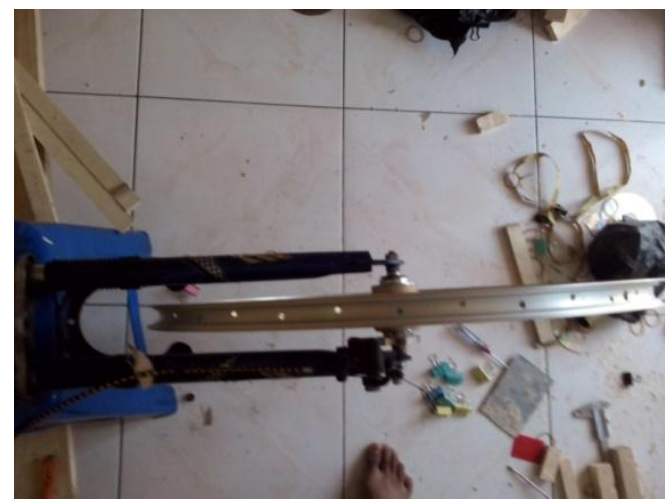

Gambar 19 Proses balancingvelg

7) Pengecatan

Pendempulan dan pengamplasan dilakukan agar diperoleh permukaan yang lebih rata. Pengecatan dilakukan dengan cat yang sesuai untuk kayu agar dapat menambah unsur estetika dari jarijari velg sepeda kayu yang dibuat.

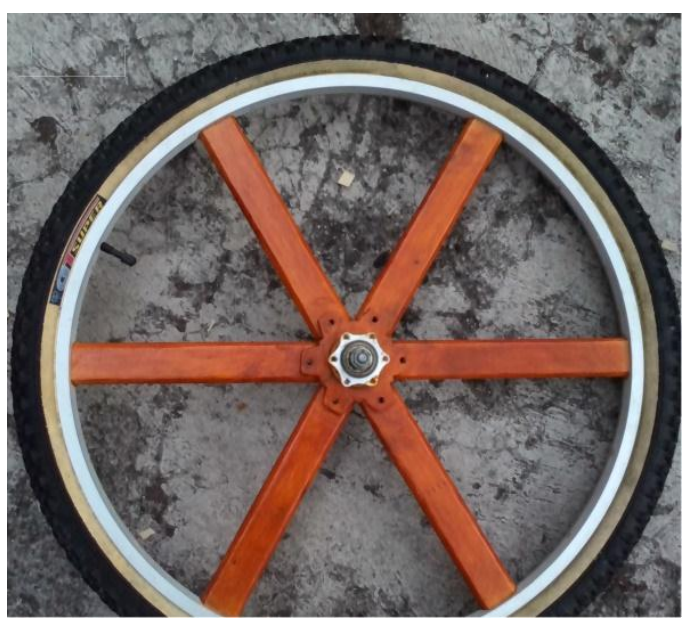

Gambar 20 Hasil pengecatan

\section{HASIL PENGUJIAN}

1) Pengujian Pembebanan Velg Sepeda Kayu

Pengujian pembebanan dilakukan dengan memberikan beban terhadap sepeda kayu. Pengujian delakukan dengan memberikan pembebanan bertahap mulai dari $20 \mathrm{~kg}$ hingga beban $70 \mathrm{~kg}$. Dengan pengujian pembebanan diharapkan dapat diketahui ketahanan velg sepeda kayu terhadap beban yang diberikan. 


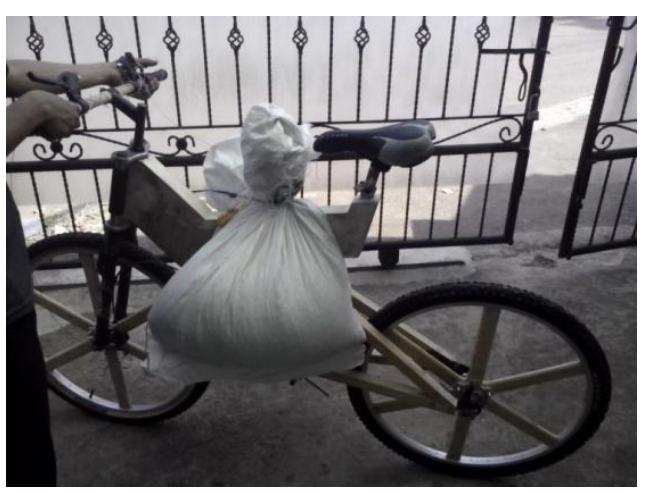

Gambar 21 Proses pengujian beban

Tabel 1. Hasil pengujian pada beban $20 \mathrm{~kg}, 30 \mathrm{~kg}$, $40 \mathrm{~kg}, 50 \mathrm{~kg}, 60 \mathrm{~kg}$, dan $70 \mathrm{~kg}$

\begin{tabular}{|l|l|c|c|c|}
\hline \multirow{2}{*}{ No. } & \multirow{2}{*}{ Part Sepeda } & \multicolumn{2}{|c|}{ Kondisi } & \multirow{2}{*}{ Keterangan } \\
\cline { 3 - 4 } & & Baik & Tidak & \\
\hline 1. & Pengunci & $\sqrt{ }$ & - & Tidak ada \\
2. & Adaptor $h u b$ & $\sqrt{ }$ & - & indikasi \\
3. & Jari- jari & $\sqrt{ }$ & - & kerusakan \\
4. & rim & $\sqrt{ }$ & - & (retak) \\
& & & & \\
\hline
\end{tabular}

Dari hasil pengujian diperoleh hasil bahwa 2 buah velg sepeda mampu menahan beban sebesar $70 \mathrm{~kg}$.

2) Pengujian Impact Jari-jari Velg Sepeda Kayu

Pengujian impact velg sepeda kayu dilakukan dengan menjatuhkan velg dari ketinggian tertentu sesuai dengan desain awal. Pengujian jarijari velg sepeda kayu dilakukan bertahap mulai dari ketinggian $2 \mathrm{~cm}$ hingga ketinggian $20 \mathrm{~cm}$, dari benturan yang terjadi ketika dijatuhkan dari ketinggian tertentu dapat diketahui kondisi ketahanan jari-jari velg sepeda kayu yang dibuat.

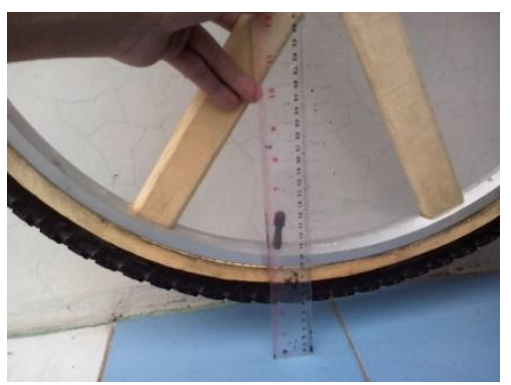

Gambar 22 Pengukuran ketinggian roda sebelum diuji impact

Tabel 2 Hasil Pengujian Impact

\begin{tabular}{|l|l|l|l|}
\hline No. & Ketinggia & Kondisi & Keterangan \\
\hline
\end{tabular}

\begin{tabular}{|c|c|c|c|c|}
\hline & $\mathrm{n}$ & Baik & tidak & \\
\hline 1. & $2 \mathrm{~cm}$ & $\sqrt{ }$ & - & \multirow{10}{*}{$\begin{array}{c}\text { Tidak ada } \\
\text { perubahan } \\
\text { pada jari- } \\
\text { jari velg }\end{array}$} \\
\hline 2. & $4 \mathrm{~cm}$ & $\sqrt{ }$ & - & \\
\hline 3. & $6 \mathrm{~cm}$ & $\sqrt{ }$ & - & \\
\hline 4. & $8 \mathrm{~cm}$ & $\sqrt{ }$ & - & \\
\hline 5. & $10 \mathrm{~cm}$ & $\sqrt{ }$ & - & \\
\hline 6. & $12 \mathrm{~cm}$ & $\sqrt{ }$ & - & \\
\hline 7. & $14 \mathrm{~cm}$ & $\sqrt{ }$ & - & \\
\hline 8. & $16 \mathrm{~cm}$ & $\sqrt{ }$ & - & \\
\hline 9. & $18 \mathrm{~cm}$ & $\sqrt{ }$ & - & \\
\hline 10. & $20 \mathrm{~cm}$ & $\sqrt{ }$ & - & \\
\hline
\end{tabular}

3) Pengujian Roda

a. Pengujian eksentrisitas (run out) lateral

Pengujian dilakukan dengan mengukur bagian terluar dari lingkaran diameter ban pada 6 titik sesuai dengan jumlah jari-jari velg, sehingga dapat diketahui selisih dari pergerakan roda ke atas dan ke bawah. Posisi titik-titik pengujian ditunjukkan pada gambar 23.

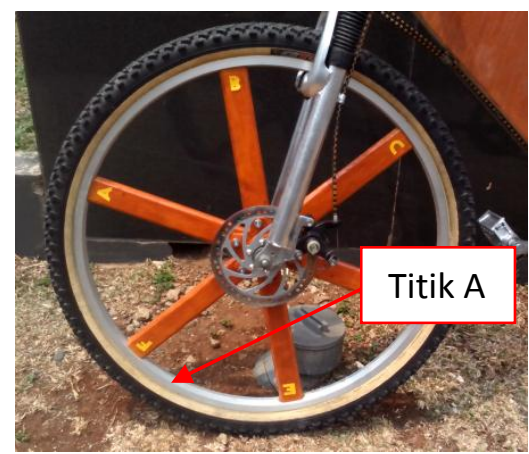

Gambar 23 Posisi titik A

b. Pengujian eksentrisitas lateral ban depan

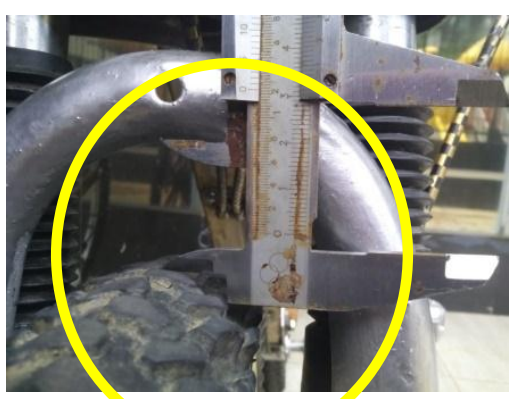

Gambar 24 Peng '1'nuran o'setrisitas lateral roda depan pada titik A 


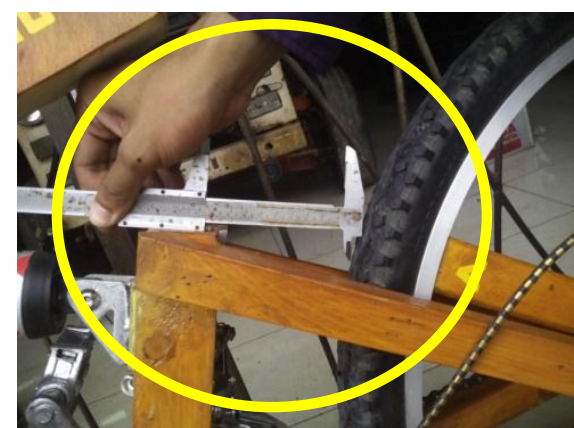

Gambar 25 Pengukuran eksetrisitas lateral roda belakang pada titik A

Tabel 3 Hasil pengujian eksentrisitas lateral dan aksial ban depan

\begin{tabular}{|c|l|c|c|c|}
\hline No. & Posisi & Lateral & $\begin{array}{c}\text { Aksial } \\
\text { kanan }\end{array}$ & $\begin{array}{c}\text { Aksial } \\
\text { kiri }\end{array}$ \\
\hline 1. & Titik A & $31 \mathrm{~mm}$ & $16 \mathrm{~mm}$ & $15 \mathrm{~mm}$ \\
\hline 2. & Titik B & $32 \mathrm{~mm}$ & $17 \mathrm{~mm}$ & $14 \mathrm{~mm}$ \\
\hline 3. & Titik C & $33 \mathrm{~mm}$ & $17,5 \mathrm{~mm}$ & $14 \mathrm{~mm}$ \\
\hline 4. & Titik D & $31 \mathrm{~mm}$ & $17,5 \mathrm{~mm}$ & $15 \mathrm{~mm}$ \\
\hline 5. & Titik E & $31 \mathrm{~mm}$ & $17 \mathrm{~mm}$ & $14 \mathrm{~mm}$ \\
\hline 6. & Titik F & $32 \mathrm{~mm}$ & $18 \mathrm{~mm}$ & $14 \mathrm{~mm}$ \\
\hline & Deviasi & $2 \mathrm{~mm}$ & $2 \mathrm{~mm}$ & $1 \mathrm{~mm}$ \\
\hline
\end{tabular}

Tabel 4 Hasil pengujian eksentrisitas lateral dan aksial ban belakang

\begin{tabular}{|c|l|c|c|c|}
\hline No. & Posisi & Lateral & $\begin{array}{c}\text { Aksial } \\
\text { kanan }\end{array}$ & $\begin{array}{c}\text { Aksial } \\
\text { kiri }\end{array}$ \\
\hline 1. & Titik A & $90 \mathrm{~mm}$ & $11 \mathrm{~mm}$ & $8 \mathrm{~mm}$ \\
\hline 2. & Titik B & $91 \mathrm{~mm}$ & $10 \mathrm{~mm}$ & $9 \mathrm{~mm}$ \\
\hline 3. & Titik C & $91 \mathrm{~mm}$ & $9,5 \mathrm{~mm}$ & $8,5 \mathrm{~mm}$ \\
\hline 4. & Titik D & $90 \mathrm{~mm}$ & $9,5 \mathrm{~mm}$ & $9,5 \mathrm{~mm}$ \\
\hline 5. & Titik E & $92 \mathrm{~mm}$ & $10 \mathrm{~mm}$ & $9,5 \mathrm{~mm}$ \\
\hline 6. & Titik F & $92,5 \mathrm{~mm}$ & $10,5 \mathrm{~mm}$ & $9 \mathrm{~mm}$ \\
\hline & Deviasi & $2,5 \mathrm{~mm}$ & $1,5 \mathrm{~mm}$ & $1,5 \mathrm{~mm}$ \\
\hline \multicolumn{5}{|l|}{ Setelah dilakukan pengujian eksentrisitas }
\end{tabular}

dan ruang bebas roda (clearance), telah didapatkan standar yang sesuai pada roda sepeda. Pergerakan roda ke atas dan bawah tidak lebih dari $4 \mathrm{~mm}$, pergerakan kekanan dan kekiri tidak lebih dari 4 $\mathrm{mm}$ begitu pula ruang bebas roda tidak kurang dari 2 mm. Sehingga dapat disimpulkan roda memenuhhi standar SNI.

\section{4) Pengujian ban dalam dan ban luar}

Ban yang diuji memiliki standar tekanan minimum sebesar 35 Psi dan tekanan maksimum sebesar 65 Psi. Pengujian ban dilakukan dengan memompa ban dengan tekanan $110 \%$ dari tekanan maksimum yang tercantum pada didnding ban. Tekanan itu dipertahankan selama minimum 5 menit dan ban harus tetap menyatu dengan baik pada velg.

Setelah diuji dengan memompa ban $110 \%$ dari tekanan maksimum ban yaitu 71,5 Psi dan dipertahankan selama minimum 5 menit. Ban tetap meyatu dengan baik pada velg sesuai dengan standar SNI.

\section{KESIMPULAN}

Dari hasil penelitian yang telah dibuat terdapat beberapa kesimpulan diantaranya yaitu:

1. Dari hasil analisis dengan menggunakan software Inventor didapatkan nilai tegangan von mises untuk jari-jari velg sebesar $11.43 \mathrm{ksi}$, besar nilai safety factor untuk jari-jari velg sebesar 3.49 dan besar nilai displacement untuk jari-jari velg sebesar 0.003942 in

2. Melalui proses analisis serta pengujian langsung, jari-jari velg sepeda kayu yang dibuat mampu untuk menahan beban sesuai dengan desain yang telah dibuat pada software Inventor. Desain jari-jari velg kayu yang telah dibuat mampu menahan beban pada saat pengujian sampai dengan pembebanan $70 \mathrm{~kg}$.

3. Dari hasil pengujian impact terhadap jari-jari velg kayu yang dibuat, jari-jari velg sepeda kayu dapat menahan benturan dari ketinggian 2 cm sampai dengan ketinggian $20 \mathrm{~cm}$.

4. Roda depan memiliki pergeseran eksentrisitas lateral maksimum sebesar $2 \mathrm{~mm}$ dan pergeseran eksentrisitas axial sebesar $2 \mathrm{~mm}$, sedangkan roda belakang memiliki pergeseran eksentrisitas lateral maksimum sebesar 2,5 $\mathrm{mm}$ dan pergeseran eksentrisitas axial sebesar 1,5 $\mathrm{mm}$.

5. Ruang bebas roda depan terhadap frame sebesar $61 \mathrm{~mm}$, terhadap garpu kanan sebesar $16 \mathrm{~mm}$, terhadap garpu kiri sebesar $14 \mathrm{~mm}$, sedangkan ruang bebas roda belakang terhadap poros arm sebesar $90 \mathrm{~mm}$, terhadap arm kanan $10 \mathrm{~mm}$, terhadap arm kiri $8 \mathrm{~mm}$. 
6. Setelah diuji dengan memompa ban $110 \%$ dari tekanan maksimum ban yaitu 71,5 Psi dan dipertahankan selama minimum 5 menit. Ban tetap meyatu dengan baik pada velg sesuai dengan standar SNI.

\section{DAFTAR PUSTAKA}

Frick Heinz, Moerdiartianto, 1799. Ilmu Konstruksi Bangunan Kayu, Kanisius

Hurst Kenneth S, 2006. Prinsip-prinsip Perancangan Teknik, PT Gelora Aksara Pratama

Ir.Ign. Puspantoro Benny, M. Sc., 2005. Konstruksi Bangunan Sambungan Kayu Pintu Jendela, Andi Yogyakarta

Kholil Ahmad, ST dkk, 2008. Elemen Mesin 1, Jakarta : Penerbit UNJ Press,

Shigley E. Joseph, Mitchell D. Larry, 1988. Perencanaan Teknik Mesin, Jakarta

Yon F, Huda, 2012. Autodesk Inventor Profesional 2012 Panduan Merancang Mesin, Andi Yogyakarta 